\title{
Bargaining options under the Employment Contracts Act
}

\author{
Pat Walsh*
}

The Employment Contracts Act is intended to influence the pattern of bargaining and the resulting contracts. This paper examines the factors that may influence employers and employees in exercising their bargaining options.

\section{Introduction}

The Employment Contracts Act is the product of deeply held grievances on the part of employers and the Government over the structure and outcomes of collective bargaining under the Labour Relations Act. It is, accordingly, designed to promote if not coerce substantial change. All employers and employees face uncertainty and potential upheaval in their bargaining arrangements under the new legislation. This article introduces some of the issues that need to be faced in considering bargaining options under the new legislation.

\section{Individual contracts}

All parties have to consider the possibility of a significant shift from collectively negotiated conditions of employment to individual contracts. Individual contracts are sometimes presented as involving one individual, the worker, negotiating directly with another individual, the employer. In fact, of course, it involves an individual worker facing a collective - an organization with far greater resources than can be mustered by an individual, whether represented by a bargaining agent or not. For this reason, workers, - especially those at lower levels in the organizational hierarchy, have historically preferred collective negotiations so as to mitigate the vulnerability of the individual. In the present economic circumstances, there does not appear to be any particular reason for these preferences to change. There will be exceptions - workers who possess skills or expertise in short supply, or whose experience or particular abilities make them essential to their organization. These workers may feel confident that their bargaining leverage is such as to overcome the potential disadvantages of bargaining as an individuall In the state sector, where collective bargaining has historically been at a much higher level than in the private sector, but where senior managers have recently shifted from collective to individual arrangements, there may be pressure for individual contracts from employees just below that level. In some small workplaces, workers may feel secure enough in their relationship with their employer that they seek individual contracts. But it is unlikely that large proportions of the workforce will seek to replace their collective contract with an individual contract of employment. It is more likely that some employees will pursue particular issues either not covered in the collective contract, or dealt with unsatisfactorily, by way of an individual contract which supplements rather than supplants their collective contract. It should not be overlooked that the Act does not

* Industrial Relations Centre, Victoria University of Wellington. 
prohibit a person negotiating a variety of contracts covering different sets of issues, providing he or she can persuade the other party to agree to this.

The main impetus for replacing collective contracts with individual contracts will come from employers. A number of issues affect an employer's decision to do this:

First, the number of employees presently covered by collectively negotiated conditions will clearly be a factor in considering whether or not to move to individual contracts. The transaction costs in negotiating large numbers of individual contracts will deter most employers unless there are other obvious advantages, or the employer is able to minimize the transaction costs, perhaps by offering a standard form contract to all employees. In the latter case, however, the employer might well be better off retaining a collective contract, as the offering of an individual contract opens the door to negotiations on an individual basis. The employer may find that the final outcomes are not at all standard. The main appeal to employers of the standard form contract approach is strategic. It divides a workforce previously employed under one contract and thereby weakens them industrially. This may then make it more feasible in future negotiations for an employer to worsen conditions for some workers, while maintaining or improving them for others. Alternatively, it may allow employers to worsen them for all workers. These objectives are normally more difficult to achieve under a collective contract. Negotiating contracts directly with the workers may also deprive trade unions or private bargaining agents of any presence in the workplace. It is obviously relevant to this issue that workers are prevented from striking over the renegotiation of an individual contract.

Second, the proportion of employees who are unionized may affect employer preferences for collective or individual bargaining. This will become a more significant factor if union density falls substantially in the next few years. If aggregate union density does fall considerably, then an employer facing a largely unionized workforce is more likely to be dealing with fairly committed union members with a strong preference for collective negotiations. In those circumstances, a push for individual contracts may not hold much appeal. In contrast, a largely ununionized workforce is most unlikely to have the inclination or the capacity to organize collectively.

Third, employers with a strong desire to reduce labour costs, or to make more flexible use of their labour resources may believe that this can be more easily achieved through individual contracts. There are, broadly, 2 routes to this conclusion, 1 highly threatening from an employee's point of view, and the other less so.

The less threatening route begins from a workforce that is highly diverse, whether because of the technology in use or the range of the organization's products or services, or because of the demographic characteristics of the workers. It may also be coupled with an assessment of the competitive position of the organization in the market and a desire to respond in more innovative ways to those competitive pressures. The employer may abelieve that the needs both of the organization and the employees may be furthered by a greater diversity of employment conditions, to the degree that this is best achieved through individual contracts. Employees with skills in short supply may share this assessment. This option is likely only to apply in small workplaces undertaking a range of productive activities or with a demographically diverse workforce. In other cases, a series of collective contracts would meet this situation better and entail lower transaction costs.

The version of this approach that workers find threatening is the straightforward desire to cut back on labour costs and lower employment conditions. This flows from the correct assessment that large categories of workers, especially the unskilled, already weakened by present labour market circumstances, are doubly disadvantaged when negotiating on an individual basis. Already we are seeing examples of this strategy in a range of contexts. Many cases have been reported of employers inducing or coercing workers to sign individual contracts which substantially worsen their employment 
conditions. The appeal of this option may have been somewhat reduced by the Labour Court's ruling in the Superstrike Bowling Centre case, 1 that neither party may unilaterally vary existing conditions of employment, and its grant of a compliance order to enforce this decision. Unless the decision is overturned on appeal, this constitutes a significant limitation on the ability of employers to achieve significant change in employment conditions through the imposition of individual contracts. In practice, of course, the key question is whether workers are able to enforce the right not to have their employment conditions unilaterally varied. They will often be unable to do so. Alternatively, workers faced with dismissal if they do not agree to changes in their employment conditions, will often consent rather than take what will seem to them to be the hazardous option of a personal grievance action with the possibility of some monetary gain many months down the track. This is particularly the case if they face an extended stand-down period for the unemployment benefit.

Fourth, in the state sector, employers may take the initiative to greatly extend the scope of individual bargaining, and further reduce the level of collective coverage. The growth of managerialism in the state sector, and the associated reduction of collective bargaining coverage since 1988, indicates a general management preference for less union influence over the determination of employment conditions. However, it cannot be immediately deduced from this that state sector management has a strong wish to take that trend even further. There may be good reasons, from management's perspective, for the retention of collective bargaining, at more or less the levels in place now. Public service employers have indicated some desire to extend the scope of individual coverage, but not to any radical degree. The transaction costs of doing so are an inhibition. However, as, noted above, pressure for individual contracts in the state sector may come as much from employees as from management. Any significant shift to individual contracts in the state sector would carry implications for the role of the State Services Commission (SSC), which is designated as the employer party for the negotiation of collective contracts, but has no statutory authority over individual contracts.

Fifth, a slightly different situation applies for those non-unionized employees in the private sector not covered by collective negotiations in the past, but rather by individual contracts of varying comprehensiveness. In the new environment, these employees may seek more elaborate contracts, particularly if they see individual contracts being negotiated for some employees previously covered by a collective document.

A final consideration is whether an organization is equipped to deal with the greater complexity required of human resource management by a shift to individual contracts. For all their faults, collective arrangements have the undoubted virtue of relative simplicity. Individual contracts may not be worth the trouble they unavoidably create.

\section{Collective contracts}

\section{The number of collective contracts}

One of the first issues to be considered is the number of collective contracts. In submissions to the Select Committee considering the Employment Contracts Bill, a number of large employers expressed grave concern at the possibility that their present satisfactory bargaining arrangements - which for those organizations meant mainly enterprise bargaining - might be disrupted by groups of employees using separate bargaining agents and seeking different collective contracts. There is nothing in the Act which specifically prevents this. Two issues arise. What is the likelihood of workers acting in this way and, if so, what are their prospects of success? 
Clearly, employees who are presently under one document are only likely to seek a range of collective contracts where they believe they are ill-served by their present bargaining arrangements. In those circumstances, their position may be an accurate assessment of the past performance of either their union, their employer or both. It may also reflect unrealistic expectations about what can be achieved. These expectations may be fed by rival bargaining agents touting for business. A sequence of bid and counter-bid will make it more difficult for any bargaining agent, including unions, to take the most rational overall view of the bargaining process, and they may feel constrained to push for a better return, particularly for disaffected groups. Dissatisfaction with a single contract may be a product of diversity, where dissimilar groups are bound into the same document and believe.their particular needs can best be furthered by a series of collective contracts. Employers may make the same judgement. But normally, it would be expected that employers will have a general preference for a single collective contract.

The prospects of these groups achieving their target depends upon their relative industrial strength under the new regime. Their inability to strike while they remain under a collective contract is a severe impediment.

\section{Bargaining agents}

State employers are in at least one unique position under the Employment Contracts Act. They do not have to decide who their bargaining agent will be. The Act, or to be precise the State Sector Act, does that for them by designating the SSC as the employer party. All other employers and employees have to make that decision. There is no shortage of potential bargaining agents from whom to choose. Indeed, among the legal profession, for whom business has been slow in recent times, there is a veritable "feeding frenzy" 2 as lawyers discover a potential area of new business. In addition, a range of new bargaining agents have established themselves, targeted chiefly at employers, but willing to represent employees as well.

Employers and employees may choose to do their own bargaining, although they should be mindful of the dictum that lawyers representing themselves have fools for clients. However, in some cases this may be a rational choice. On the employee side, some particular individuals or even small groups may have the requisite skills to negotiate on their own behalf. Many firms will also prefer to represent themselves, either because of size or because of management's industrial relations expertise. For employers the choice of bargaining agent may be difficult. Some may be able to continue to rely upon an employers organization, but for many this will not be possible. Legal firms and other private bargaining agents are mostly untried in the field, and there will probably be a difficult period as reputations are gained and lost and employers assess who can be relied upon. Many firms will choose to develop their own industrial relations or human resource management expertise to cope with the new regime.

For workers who do not wish to represent themselves, the choice is whether to join or remain a member of the union that has traditionally had coverage over their work, switch to another union or engage a bargaining agent. Most workers are likely to find union representation the most cost effective option, particularly when considering the long-term administration of the contract. This is most obviously the case so far as personal grievances are concerned, where most individuals will find the costs of hiring a lawyer or other agent to represent them to be prohibitive. Unions have, however, traditionally offered their members uniform solutions to general problems. Where groups of members believe they have particular concerns which are not being met by their union, then a different union or a bargaining agent becomes more attractive. All unions have

2 I gratefully acknowledge John Robson, a lawyer himself and one who understands the legal profession and their little ways, for this vivid metaphor. 
disaffected groups, if only as a consequence of majority rule within the organization. Where there are stable majorities and minorities, the latter, given a choice of representation for the first time, may choose to exercise that choice.

Both parties have to decide whether they will negotiate, and, if so, with which bargaining agent. It remains a curious anomaly in an Act that goes to remarkable lengths to ensure that bargaining agents are properly authorized and accountable to their constituents, that there is no guarantee that the other party will in fact bargain with the duly authorized agent. Part of the decision involves an assessment of what constitutes authorization to negotiate. Although the Act is silent on this matter, employers do not have complete discretion, inasmuch as the Employment Court is likely to look askance at any effort to by-pass an agent obviously authorized by virtue of signatures or some other clear evidence. Nonetheless, employers do have some discretion in deciding what they will accept as evidence of authorization. It is already apparent that some employers are strongly disputing union claims to be an authorized bargaining agent. The Government's refusal to adopt the American model - followed so closely in other parts of the Act - of an exclusive bargaining agent authorized by majority vote is designed to allow employers to follow this strategy. This will not be an issue for workers, as it will be self-evident who the authorized bargaining agent is for their employer. They will have no choice if they wish to negotiate.

Employers, however, may face an array of choices - the union that has traditionally represented their workers, other unions claiming to represent particular groups of employees, various private bargaining agents, or, of course, individuals representing themselves. Employers enjoy some discretion, at least theoretically, about which of these bargaining agents they will in fact negotiate with. The decision will depend partly on prior choices about the number and mix of individual or collective contracts in the organization. Other factors to take into account are the degree of professionalism of the various bargaining agents and the likelihood of a satisfactory relationship being established for the future management of the contract. The employer will also take heed of the distribution of employee preferences about bargaining agents, and is likely to feel more confident about excluding an agent favoured by only a small minority of workers. Wider strategic factors are also likely to feature in the decision. Where employers want to embark on a union-avoidance or union-busting strategy, they will actively favour nonunion bargaining agents, or will seek to exclude or marginalize the union in other ways. It is already clear that a number of firms have adopted this strategy. Equally, if an employer prefers to deal with a bargaining agent knowledgeable about the industry or enterprise concerned and the needs of both employers and employees located there, they will tend to prefer to negotiate with unions.

\section{Multi-employer contracts in the private sector}

The Employment Contracts Act rules out the large subsequent parties awards which encompassed thousands of employers and employees simply by virtue of the blanket coverage facility in the Labour Relations Act. However, there is nothing in the Employment Contracts Act which actually prohibits multi-employer contracts. Nonetheless, the statutory prohibition on strikes as a way of coercing an employer to become a party to multi-employer negotiations, does mean that employers have complete discretion over whether or not to enter multi-employer negotiations or to press ahead with enterprise bargaining. In one sense, the tables are turned from the Labour Relations Act where (until a belated amendment in 1990) unions controlled the decision as to whether an employer would be party to the award or be cited out for an enterprise agreement.

Under the Labour Relations Act, unions exercised that choice decisively in favour of retaining award coverage. Under the Employment Contracts Act unions are deprived of the legislative levers that sustained multi-employer documents in the past. Securing 
multi-employer contracts will depend on employer acquiescence, or the now more hazardous strategy of deploying industrial muscle. It is quite likely, however, that some employers will prefer to retain multi-employer documents. Research by McAndrew and Hursthouse (1990) indicates some measure of satisfaction among small employers over the award system. Employers are likely to opt for multi-employer bargaining where they actively want wages and employment conditions to be taken out of competition, traditionally one of the major justifications for the award system in New Zealand. This was historically often coupled with protectionist economic policies which sheltered domestic producers against external competition, whilst the award system eliminated domestic competition over the recruitment and retention of labour and its cost. Deregulation has eliminated much of this rationale for multi-employer contracts, but not all, and there will still be some cases where it remains a rational approach. This is particularly so where standardized production systems reduce the pressure for flexible and innovative use of labour. Multi-employer negotiations may also be favoured in particular sectors, such as the dairy industry, where a small number of major employers can be coordinated through a strong central body. In addition, many smaller employers prefer to join multi-employer negotiations either because they lack the resources or the expertise to do it themselves, or because they do not want to negotiate directly with their own employers. Equally, however, small employers may prefer to negotiate directly with their employees, either because they have a good relationship with them - or wish to develop one - or because they see this as a way of cutting labour costs. As noted above, there is already some indication that the latter strategy is being adopted in a number of cases.

\section{Multi-employer bargaining in the state sector}

Circumstances are quite different in the state sector, where the statutory role of the SSC as employer party leaves it well placed, should it so choose, to ensure the continuation of the multi-employer bargaining which has developed in health and education. The SSC negotiates multi-employer documents on behalf of (and in consultation with) the area health boards and the various education employers. The future industrial relations regime for the health sector is of course quite uncertain following the Government's decision to replace area health boards with regional health authorities which will be essentially purchasers of services from public and private providers.

For the SSC, a major problem in contemplating a move away from national bargaining is the fiscal constraint and the desire of the Government to retain central control over wage outcomes through the SSC. On the face of it, a stern cash limits policy, in which central government absolutely refuses to allocate any extra resources to compensate for unwise wage settlements, should do the trick. But in practice, matters might not be so straightforward, and a strategy which prevented the question of demand for extra resources from ever arising has greater fiscal appeal to the Government and the SSC. Even the present system offers no absolute guarantee of fiscal control, as shown by the overrun in teachers' pay in 1990-91 and the necessity for supplementary estimates to be voted to make up the shortfall.

Regardless of the size of any sub-national settlements, there is also concern over the potential relativity impact of uncoordinated settlements. Transaction costs for the SSC would also be higher. Nonetheless, there remains a potential contradiction between the Government's stated industrial relations policy which is to encourage enterprise bargaining, and a continuation of national multi-employer bargaining in health and education. However, the Government's policy is also that employers - and employees should be able to choose the type of bargaining they prefer, and so the question arises as to whether either party in health or education might choose to move away from national bargaining. 
There is as yet no indication that unions in either the health or education sectors have any desire to shift away from national bargaining. For their part, employers are more likely to opt for sub-national bargaining where they believe they operate principally in a regional labour market, where funding and budgetary development is regionally based and where the transaction costs of doing so are acceptable.

In the health sector, regional bargaining had understandable appeal to some area health boards as a response to the increasing diversity and difficulty of their budgetary positions, and this appeal may have grown in the near future. However, their enthusiasm was tempered by their reliance upon a national labour market for medical and nursing staff and senior management. On the other hand, separate contracts could also be seen as a way of overcoming medical staff shortages. Transaction costs would have been lower than under the present arrangements. The boards had, in fact, prior to their abolition, proposed separate regional documents for junior doctors. This proposal continues under the new regime of commissioners and is being resisted by the doctors' union. The new regional health authorities will presumably not be large employers and will deal regionally with their mostly administrative staff. The proposed relationship between public health providers, particularly the Crown health agencies, who will be large employers, and the SSC in the new regime is unknown at this stage.

In the education sector, the existence of a national labour market for all teaching staff encourages retention of multi-employer documents. Boards or councils which face difficulties in attracting staff in particular subjects or disciplines, or to particular geographical areas, may be willing to pay a premium to overcome this problem, although ranges of rates could also solve it. Bulk funding of the compulsory sector would not necessarily lead to lower level determination of pay and conditions. It has not done so in the tertiary sector. However, to the extent that the Government wishes to put in place a regime which actively encourages competition among educational institutions, then a move to enterprise bargaining is more likely. The transaction costs of enterprise bargaining would be prohibitively high in the pre-school and primary sectors, less so in secondary but possibly lower than at present in tertiary.

\section{Enterprise bargaining}

One of the most striking developments in bargaining since 1987 is the contrasting fate of enterprise bargaining in the private and public sectors. Harbridge (1991) has shown that there has been a precipitate fall in the number of workers covered by single employer agreements in the private sector. The chief reason for this, of course, was the single set of negotiations principle in the Labour Relations Act, by which second tier bargaining was eliminated, forcing unions to choose between awards and single employer documents. The public service, by contrast, moved from centralized service-wide occupational bargaining to enterprise bargaining.

Employers and employees covered by enterprise documents are well placed to continue those arrangements under the Employment Contracts Act. But in all cases, this depends upon the willing cooperation of all individuals involved. Their cooperation cannot be coerced as in the past. The preservation of an enterprise agreement may be jeopardized by the defection of one or more individuals or groups, whether on an occupational basis or not, whether through their union or another union, by using a separate bargaining agent or by representing themselves. Obviously, their capacity to defect successfully and secure a separate contract will depend on relative bargaining strength. This will tend to be in the employer's favour at the moment, but will not always be so, and even in the present labour market circumstances there are particular groups in an organization whose attempt to defect from the enterprise contract would be either successful or highly disruptive (or both). Employers and unions in the private 


\section{4}

Pat Walsh

sector who have recently completed an enterprise document after protracted difficulties are unlikely to want to see that hastily thrown away.

The status quo option may be feasible in the public service (and in quangos and other Crown agencies), where at present the SSC and the Public Service Association (PSA) negotiate national departmental documents, covering the vast majority of employees, supplemented by a small number of individual contracts for senior and middle management. These structural circumstances of one employer party and one union party are conducive to the preservation of those arrangements. The fiscal constraint encourages the SSC to keep central control over negotiations, and limited resources means that it will prefer to keep the number of documents manageable. It is possible that the Government or the SSC might consider regional bargaining for the public service. Regional labour markets operate at the entry grades for clerical, labouring, trades and related staff, but funding remains nationally based. For middle level positions and up, and for all specialist positions, there is a tendency for a national labour market to apply. The PSA has indicated a general preference for the retention of national enterprise documents. The main threat to their preservation will come from particular disaffected groups, some of whom will no doubt switch to other bargaining agents. Public service employers will have to consider their response to that development.

\section{Conclusion}

Wholesale radical change to bargaining arrangements is unlikely in the immediate future. Nonetheless, no observer can fail to be struck by the pace and scope of change in the short period since the Employment Contracts Act came into effect. Many employers have taken swift advantage of the new possibilities now open to them. More worryingly, the Act has contributed to a sense among some employers that they now rule the workplace, unrestrained by unions or collective bargaining requirements. This paper has outlined some of the complex issues to be considered in any assessment of bargaining options under the Act. Based on past experience we can be sure that there are many issues and possible outcomes that neither this nor other commentaries have yet identified. In other words, we should expect the unexpected.

\section{References}

Harbridge, R. (1991) Collective bargaining and the Employment Contracts Bill. Paper presented to the Employment Contracts seminar, Industrial Relations Centre, Victoria University of Wellington, 15 February 1991.

McAndrew, I. and Hursthouse, P. (1990) Southern employers on enterprise bargaining New Zealand journal of industrial relations 15(2): 117-128 